certainly agree that if we say that culture influences behaviours (or actions as anthropologists would rather say), then we are indulging in a category error. 'Culture', however we define it, represents a society with all its conflicts and contradictions and its relationship with other societies; the boundaries are arbitrary. I am increasingly wondering if political is not quite simply a better term than cultural.

I am not altogether sure what families are, nor am I convinced that they are things which people generally live in and which ultimately determine their lives: socialising institutions doubtless, but not socially determining institutions.

Department of Anthropology

University College London

Gower Street

London WCIE 6BT

\section{Impact of participating in research}

SIR: Ben-Arie et al's study (Journal, January 1990, 156, 37-39) prompted us to conduct a similar one, examining the effect of research on psychiatric admissions and other psychiatric contacts, using a more specific group (depressed in-patients) and over a more immediate follow-up period.

We have re-analysed the data for 57 depressed inpatients who participated in one of the Nottingham electroconvulsive therapy (ECT) studies (Gregory et al, 1985). Using the Nottingham case register, we have compared their outcome at six months with that of 38 other patients who satisfied the entry criteria for the ECT study but did not enter, mainly due to lack of consent, and who were thus not followed up by the research team. In this example, as in that of Drs Ben-Arie et al, the clinical and research teams were separate.

We found no statistically significant differences between the two groups as regards the number and lengths of hospital or day-care admissions. The number of out-patient and other contacts were also similar for both groups.

These results suggest that participating in research did not have a significant effect on short-term outcome for these depressed in-patients. Although the two groups were not randomly allocated, demographic variables and mean index admission scores on the MADRS and HAM rating scales for the two groups were not significantly different. In contrast to the study of Drs Ben-Arie et al, the mean number of previous admissions and the mean length of the index admission were also similar for both groups.

It may be that the effect of research on admissions only becomes evident after six months. However, another more intriguing possibility is that the effect of research may be inversely proportional to the number of projects undertaken in any given clinical setting. The demographic profile of Nottingham lends itself to clinical research, and the frequency of such work here may have acted to desensitise patients and clinicians to its disturbing effects on presentation and clinical practice.

Denis O'Leary Alan LeE

University Hospital

Queen's Medical Centre

Clifton Boulevard

Nottingham

Mapperley Hospital

DAVId GiLl

\title{
Reference
}

Gregory, S., Shawcross, C. R. \& Gill, D. (1985) The Nottingham ECT study: a double-blind comparison of bilateral, unilateral, and simulated ECT in depressive illness. British Journal of Psychiatry, 146, 520-524.

\section{Genital self-mutilation}

SIR: Walter \& Streimer (Journal, January 1990, 156, 125-127), in a case report of genital self-mutilation in a non-psychotic adult male, indicated that "The patient's father... was remembered as punitive and distant. The patient's mother was more available but was perceived as devaluing and affectionless", and stated that "The nature and dramatic culmination of the patient's dysmorphophobic symptoms may be understood in terms of a childhood during which he was demoralised, emasculated, and deprived of recognition". Finally, they emphasised that nonpsychotic genital self-mutilation, while uncommon, may not be as rare as is generally stated.

However, the authors did not mention the cases of genital self-mutilation which occurred during the ancient mediterranean rites. In 1922, Frazer reported that the Great Mother Cybele's worship required from followers a ceremonial genital self-mutilation in recollection of the Attis' mythological experience.

Men who intentionally mutilate their own genitals are likely to be psychotic, and their behaviour may be considered as an acute psychotic breakdown in the context of a schizophrenic regression. Indeed, it should be conceived as an attempt to return to the mother's womb (Roccatagliata, 1982).

Roth \& Ball (1963) found that, in a high proportion $(94 \%)$ of male cases of transsexuality, there had been extreme dependence on and a strong preference for the mother of the family, and the father of 